\title{
Primeira ocorrência de Thelypteris villosa (Link) C. F. Reed (Thelypteridaceae) para o Nordeste do Brasil ${ }^{1}$
}

Taís Soares Macedo ${ }^{2,4}$, Aristóteles Góes Neto² e Fabiana Regina Nonato ${ }^{3}$

Recebido em 29/06/2010. Aceito em 21/06/2011

\section{RESUMO}

(Primeira ocorrência de Thelypteris villosa (Link) C. F. Reed (Thelypteridaceae) para o Nordeste do Brasil). Thelypteris villosa (Link) C. F. Reed, espécie rara, até recentemente tratada como endêmica da Floresta Atlântica do Estado do Rio de Janeiro, é referida pela primeira vez para a região Nordeste do Brasil, Estado da Bahia, contribuindo para ampliar as informações a respeito da espécie.

Palavras-chave: Thelypteris, samambaias, Floresta Atlântica, Bahia

\begin{abstract}
(First Record of Thelypteris villosa (Link) C. F. Reed (Thelypteridaceae) from Northeast Brazil). Until recently, Thelypteris villosa (Link) C. F. Reed, a rare species, was thought to be endemic to the Atlantic Forest in the state of Rio de Janeiro. This species is reported for the first time for Northeast of Brazil (Bahia), which helps increase what is known about this taxon.
\end{abstract}

Key words: Thelypteris, ferns, Atlantic Forest, Bahia State

Nos levantamentos envolvendo samambaias realizados no Brasil, uma das famílias que se destaca em número de espécies é Thelypteridaceae, a qual distribui-se, principalmente, nos trópicos e subtrópicos e possui aproximadamente 900 espécies em dois gêneros (Salino \& Semir, 2002). O gênero Thelypteris Schmidel é o maior, em número de espécies, e está representado no país por cerca de 84 espécies (Salino \& Semir, 2002).

Salino \& Semir (2003), ao realizarem um estudo taxonômico das Thelypteridaceae no Sudeste do Brasil, destacam a ocorrência de duas espécies raras: Thelypteris polypodioides (Raddi) C.F. Reed e Thelyperis villosa (Link) C. F. Reed, esta última, até então, considerada endêmica da Floresta Atlântica do Estado do Rio de Janeiro.

No presente trabalho registrou-se a ocorrência de Thelyperis villosa para a região Nordeste do Brasil, em um enclave de Floresta Atlântica no semi-árido do Estado da Bahia, contribuindo para ampliar as informações a respeito da espécie.
A área de estudo está localizada no município de Santa Teresinha, Estado da Bahia, mais especificamente no distrito de Pedra Branca. Corresponde a um pequeno maciço de morros conhecido como Serra da Jiboia, nas coordenadas geográficas de $12^{\circ} 51^{\prime}$ S e $39^{\circ} 28^{\prime} \mathrm{W}$. A região abriga grande diversidade de tipos vegetacionais, com caatinga na base, mata higrófila na encosta e campo rupestre no topo (Queiroz et al., 1996). Segundo Juncá (2006), é um dos pontos mais ocidentais da Floresta Atlântica baiana e uma das matas úmidas de encosta situada mais ao norte do Estado. Os espécimes coletados foram depositados no Herbário da Universidade Estadual de Feira de Santana (HUEFS) e duplicatas foram enviadas ao Herbário da Universidade Federal de Minas Gerais (BHCB). O material foi identificado a partir dos dados disponíveis em Salino \& Semir (2003).

Thelypteris villosa foi encontrada, na área de estudo, como terrícola no interior da mata, em terreno plano ou íngreme. Contudo, o hábito rupícola foi citado por Salino \& Semir

\footnotetext{
${ }^{1}$ Parte da dissertação de Mestrado da primeira Autora

${ }^{2}$ Universidade Estadual de Feira de Santana, Programa de Pós-Graduação em Botânica, Departamento de Ciências Biológicas, Feira de Santana, BA, Brasil

${ }^{3}$ Centro de Pesquisas Gonçalo Moniz - FIOCRUZ, Salvador, BA, Brasil

${ }^{4}$ Autora para correspondência: taismacedo10@yahoo.com.br
} 

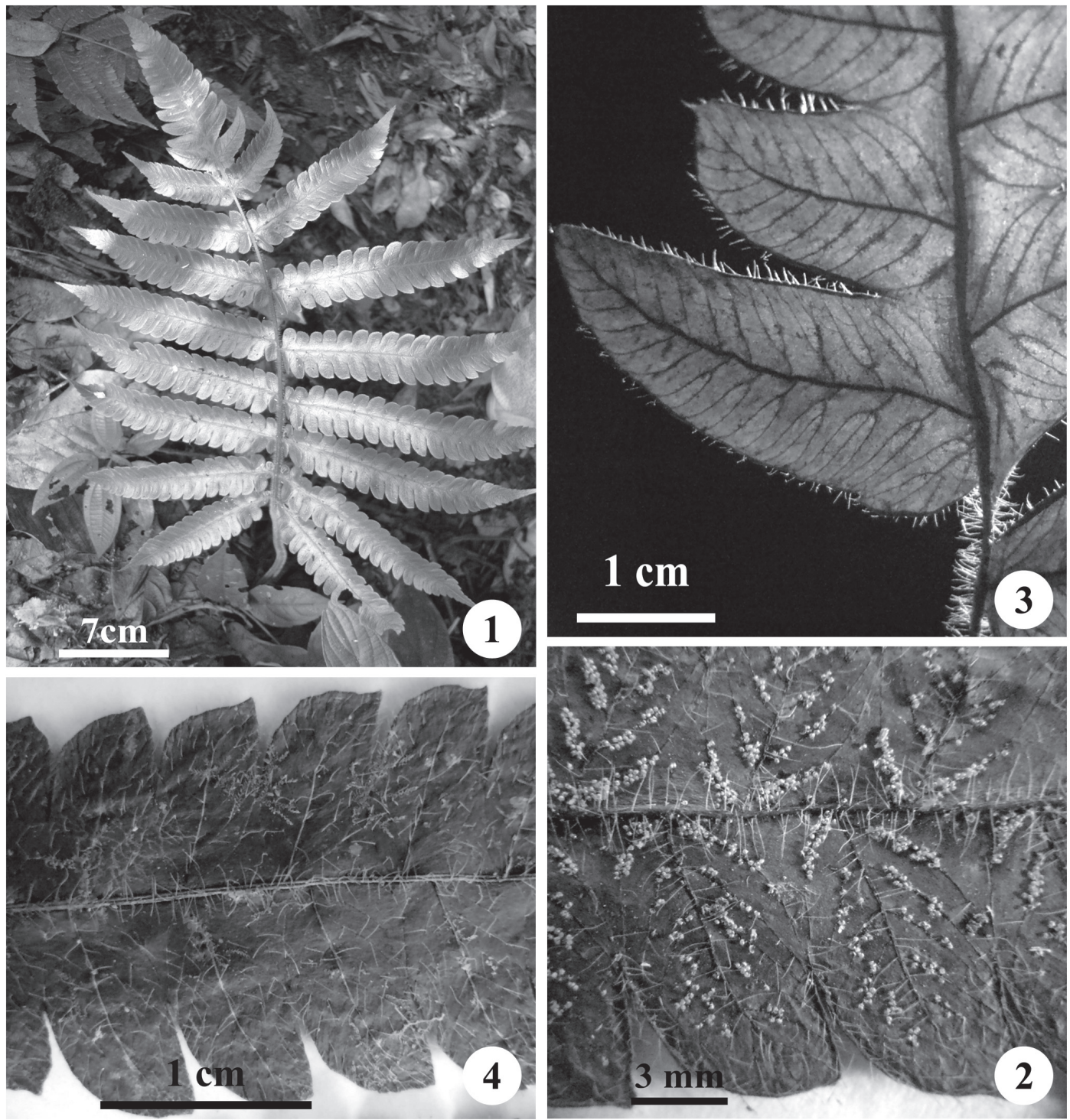

Figura 1-4. Thelypteris villosa. 1. Hábito. 2. Segmentos de uma pina mediana: detalhe da face abaxial no material herborizado. 3. Segmentos basais do ápice da lâmina: detalhe das nervuras furcadas. 4. Face adaxial da lâmina: detalhe do indumento.

(2003) para os exemplares do Rio de Janeiro. Foi coletada a aproximadamente 690-800 $\mathrm{m}$ de altitude, formando uma população de indivíduos isolados (Fig.1-4). Thelypteris villosa é uma espécie rara e endêmica do Brasil, com registros apenas para o Rio de Janeiro e Bahia (T.S. Macedo 92, 168), tendo sido coletada anteriormente em 1968 no Estado do Rio de Janeiro.

\section{Agradecimentos}

O primeiro autor agradece aos seus familiares pela ajuda durante o trabalho de campo e ao CNPq pela bolsa de Mestrado concedida. Agradecemos também ao Dr. Alexandre Salino, curador do BHCB, pela confirmação da espécie, ao PPGBot/
UEFS, ao HUEFS e seus funcionários pelo apoio logístico e infraestrutura fornecida durante a realização do trabalho.

\section{Referências bibliográficas}

Juncá, F.A. 2006. Diversidade e uso de hábitat por anfíbios anuros em duas localidades de Mata Atlântica, no norte do estado da Bahia. Biota Neotropica 6(2): 1-17.

Queiroz, L.P.; Sena, T.S.N \& Costa, M.J.S.L. 1996. Flora Vascular da Serra da Jibóia, Santa Terezinha - Bahia. I. O Campo Rupestre. Sitientibus 15:27-40.

Salino, A. \& Semir, J. 2002. Thelypteridaceae (Polypodiophyta) do Estado de São Paulo: Macrothelypteris e Thelypteris subgêneros Cyclosorus e Steiropteris. Lundiana 3(1): 9-27.

Salino, A. \& Semir, J. 2003. Notas sobre duas espécies de Thelypteris Schmidel (Thelypteridaceae - Pterophyta) do Brasil. Acta Botanica Brasilica 17(4): 515-521. 